\title{
AS MUTAÇÕES NO MUNDO DO TRABALHO NA ERA DA MUNDIALIZAÇÃO DO CAPITAL E A PRECARIZAÇÃO DO TRABALHO DOCENTE
}

\author{
Marco Antônio de Oliveira Gomes \\ Universidade Federal de Rondônia. \\ marcooliveiragomes@yahoo.com.br \\ Anselmo Alencar Colares \\ Universidade Federal do Oeste do Pará \\ anselmo.colares@ hotmail.com \\ Maria Lilia I. Colares \\ Universidade Federal do Oeste do Pará \\ lilia.colares@ hotmail.com \\ Tânia Suely A. Brasileiro \\ Universidade Federal de Rondônia. \\ taniabrasileiro@gmail.com
}

\section{RESUMO}

Este trabalho apresenta instrumentos analíticos para compreender as mutações do mundo do trabalho e a precarização do trabalho docente. Em um cenário histórico que muitos intelectuais advogam o fim do trabalho e das classes sociais, buscamos através das lentes do marxismo compreender as transformações ocorridas nas relações de trabalho e seus desdobramentos na configuração da classe trabalhadora, assim como os reflexos no trabalho docente. Nosso objetivo é situar a precarização do trabalho docente dentro de uma realidade material marcada pelos antagonismos de classe em que o capital se apropria do conhecimento como um dos instrumentos de dominação.

Palavras-chaves: Trabalho docente; classe trabalhadora; neoliberalismo; toyotismo.

\section{CHANGES IN THE WORLD OF WORK IN THE AGE OF CAPITAL MUNDIALIZATION AND PRECARIZATION OF TEACHERS JOB}

\begin{abstract}
This paper presentes analytical tools to understand the changing world of work and casualization of teaching. In a historical bachground that many intellectuals advocating the end of work and social classes, we look through the lens of Marxism to understand the transformations in labor relations and its consequences in configuration of the working class, as well reflections on the teaching work. Our goal is to situate the precariousness of teaching within material reality marked by class antagonisms in which capital appropriates the knowledge as an instrument of dominantion.
\end{abstract}

Keywords: Teaching work; working class; neoliberalism; toyotism. 


\section{Introdução}

A razão deste artigo é analisar as principais transformações ocorridas no mundo do trabalho, apontando para um caminho diferente daqueles que defendem a tese do fim do trabalho, e com ele a classe trabalhadora. Em um segundo momento, buscaremos apresentar a reestruturação do capital sobre o trabalho docente, que tem implicado na aceleração da mercantilização do ensino e rebaixamento da educação escolar. A análise do processo de precarização e intensificação do trabalho docente será insuficiente se não levarmos em conta as transformações ocorridas no mundo do trabalho nas últimas décadas, que reduz o conjunto de trabalhadores estáveis por meio de empregos formais e gera simultaneamente o surgimento de trabalhadores terceirizados e subcontratados. A produção acadêmica sobre as alterações no mundo do trabalho e na classe trabalhadora indicam que a reestruturação produtiva, na era da acumulação flexível, constitui uma das respostas da burguesia à crise de acumulação do capital. Para atingirmos nosso objetivo, à luz da crítica marxista, tomamos como parâmetros de nossas reflexões autores como Antunes (1995 e 1999), Frigotto (1995 e 1996), Mészáros (2002), Chesnais (2008), dentre outros.

\section{Apontamentos para caracterização das transformações ocorridas nas relações capital e trabalho (1970-2011): da crise do fordismo/taylorismo ao toyotismo.}

Partimos de uma fotografia panorâmica do mundo do trabalho nas últimas décadas. De saída, a imagem que observamos revela a ofensiva do capital com crescente fragilização dos trabalhadores e suas organizações, expressa no crescente desemprego e precarização das condições de trabalho daqueles que vendem sua força de trabalho no mercado. A exploração dos trabalhadores alcança níveis inimagináveis, mesmo nas nações capitalistas hegemônicas.

Nas últimas três décadas, sob os ditames do "regime de acumulação com dominância financeira", o capitalismo se expande excluindo, colocando "para fora" grandes contingentes de trabalhadores, substituindo-os pelo "trabalho objetivado" trabalho morto. É a dominação social concretizando-se na tensa dialética dos processos de exclusão e das formas precárias de inclusão. (CARVALHO; GUERRA, 2008, p. 93)

Os desdobramentos das transformações na organização da produção, quanto da ditadura do sistema financeiro para a classe trabalhadora são desesperadoras. Nesse ambiente marcado pela hegemonia das ideais liberais alguns advogam o "fim da história" e do trabalho. Essas noções supostamente científicas apontam para um mundo de relações sociais "naturalizadas" e a-históricas. Os liberais louvam as potencialidades e benefícios da racionalidade do capital, causa pela qual defendem o aniquilamento de todo e qualquer limitação à livre e plena mobilização do capital. As nações capitalistas hegemônicas são apresentadas como modelos a serem perseguidos.

Todavia, faz-se importante pensarmos em uma leitura diferente da história no plano epistemológico, para não sucumbirmos as armadilhas da visão pós moderna. Como se sabe, qualquer atividade desenvolvida no âmbito das relações humanas é histórica. Logo, é óbvio que desde suas origens a classe trabalhadora sofreu modificações decorrentes das transformações que ocorreram no âmbito da produção, mas também das lutas travadas pelos trabalhadores. 
Ora, afirmar que as formas de organização do trabalho sofreram profundas transformações não implica em negarmos a centralidade do trabalho. Afinal, não existe capital se não existe exploração do trabalho, e o que gera mais-valia é o trabalho vivo. Dessa forma, é um discurso vazio afirmar que o trabalho acabou, e quem trabalha sabe disso. Como afirma Coutinho, se mudaram as formas de trabalho, então a centralidade do trabalho não pode ser mais pensada de modo simplista, como seria, por exemplo, persistir na identificação entre o mundo do trabalho e a classe operária fabril. (2002, p. 38)

Neste quadro de transformações no mundo do trabalho, buscamos analisar a configuração assumida pela classe trabalhadora no início deste século, que evidentemente não é igual àquela existente no alvorecer do século XIX. As observações de Antunes (1995 e 1999) evidenciam que a classe trabalhadora é composta pela totalidade dos assalariados, homens, mulheres que vivem da venda da sua força de trabalho, não se restringindo aos trabalhadores manuais diretos, mas congregando igualmente os trabalhadores que vendem sua força de trabalho como mercadoria em troca de salário. Nesse sentido, concordamos com Antunes quando afirma que apesar das mudanças no interior da classe daqueles que "vivem do trabalho", não está em vias de desaparição. Como explica Antunes:

A expressão "classe-que-vive-do trabalho", que utilizamos nesta pesquisa, tem como primeiro objetivo conferir validade contemporânea ao conceito marxiano de classe trabalhadora. Quando tantas formulações vêm afirmando a perda da validade analítica da noção de classe, nossa designação pretende enfatizar o sentido atual da classe trabalhadora, sua forma de ser. Portanto, ao contrário dos autores que defendem o fim das classes sociais, o fim da classe trabalhadora, ou até mesmo o fim do trabalho, a expressão classe-que-vivedo-trabalho pretende dar contemporaneidade e amplitude ao ser social que trabalha, à classe trabalhadora hoje, aprender sua efetividade sua processualidade e concretude. (ANTUNES, 1999, p. 101)

A noção ampliada de classe trabalhadora proposta por Antunes deve ser compreendida a partir das especificidades históricas das últimas décadas. Aqueles que vendem sua força de trabalho no mundo contemporâneo enfrentam circunstâncias histórico distantes dos trabalhadores que os precederam ao longo do século XIX, mas isso não denota, como lembra Antunes, que a exploração do trabalho tenha chegado ao fim. Dito de outra forma, a configuração atual da classe trabalhadora é mais ampla que o proletariado industrial do século XIX, mas continua excluída dos processos decisórios e da riqueza socialmente produzida.

Ainda segundo Antunes, a classe-que-vive-do-trabalho congrega a totalidade daqueles que vendem sua força de trabalho, tendo como núcleo central os trabalhadores produtivos, mas também incluindo trabalhadores improdutivos, aqueles cujas formas de trabalho são empregadas como serviço, seja para o uso público ou para o capitalista, e que não se constituem como elemento absolutamente produtivo, como elemento vivo do processo de valorização do capital e de criação de mais valia. O trabalho improdutivo abrange um extenso segmento de assalariados, desde aqueles inseridos na esfera de serviços, comércio, bancos, turismo, serviços públicos etc., até aqueles que realizam atividades nas fábricas mais não criam diretamente valor. (1999, p. 102)

$\mathrm{Na}$ verdade, as mudanças no interior do mundo do trabalho não se esgotaram, pois é um processo continuado de transformações históricas engendradas dentro das relações capitalistas de produção. Parece-nos importante alertar, sem cair em generalizações abstratas, 
que a atuação configuração da classe-que-vive-do-trabalho teve suas origens com a crise do fordismo/taylorismo. Vejamos os apontamos de Chesnais:

As duas últimas décadas trouxeram mudanças muito importantes tanto nas condições de contratação e de remuneração dos assalariados como também nas condições da sua subordinação à hierarquia nas fábricas e no funcionalismo. Sobre todos estes aspectos, as relações entre o capital e o trabalho foram fortemente em benefício do primeiro. Em muitas partes do mundo, esta modificação comportou uma degradação da situação dos assalariados, principalmente em termos de perda de estabilidade e e segurança no emprego. (CHESNAIS, 2008, p. 11-12)

Reforçando a tese de Chesnais, diríamos que a reestruturação produtiva eliminou postos de trabalho ao mesmo tempo que produziu outras formas de precarização e intensificação, eliminando os empregos tradicionais, de tempo integral e de duração indeterminada. Dessa forma, o atual desenho social no mundo do trabalho modificou profundamente o estatuto dos assalariados e as condições de emprego. Trata-se cada vez mais de empregos desqualificados, pouco atraentes e mal remunerados. De fato, o amplo desenvolvimento tecnológico (a automação, a robótica e a microeletrônica) que invadiu o processo produtivo no interior da fábrica, inspirado no modelo toyotista, amoldou um modelo de organização mais desregulamentado das relações de trabalho. Lembremo-nos que as tecnologias da informação e da comunicação permitem ao capital reduzir a demanda por trabalho, além de transferir a produção para regiões subordinadas onde o custo de trabalho é menor.

(...) Para o capital, quanto menor a presença do trabalho vivo, menor se faz o custo da produção.

Assim a tecnologia e ciência, estreitamente limitadas pelas determinações fetichistas do capital, geram, no dizer de Mészáros, o "downsizing produtivo" que, em nome do avanço tecnológico, lançam massas de trabalhadores no desemprego, aumentando, num crescente espiral, a insegurança do trabalho. De fato, nesse mundo louco do downsizing, a tecnologia parece ter assumido uma forma independente de vida, com vontade própria e poder incontestável de tomada de decisão, deixando o sujeito humano real à mercê de determinações desumanas. (CARVALHO; GUERRA, 2008, p. 96-97)

Portanto, na realidade contemporânea, podemos afirmar que o tema do desemprego não é uma questão passageira atrelada a uma crise de conjuntura das relações de produção, que uma vez superado, reabsorveria uma fatia considerável dos desempregados. Na verdade, os empregos perdidos não mais voltarão. Em outras palavras, trata-se de uma crise estrutural do capital e de sua incapacidade civilizatória.

Nesse sentido, a desregulamentação das relações trabalhistas impulsiona o surgimento de trabalhadores subcontratados e informais; precarização do trabalho com ampliação de jornadas, horários flexíveis, banco de horas e todo o glossário de expressões de destituição dos direitos trabalhistas. Além dos fatos apontados, o trabalho em domicílio é reinventado. Esta tendência alcança de forma diferenciada tantos as nações centrais do capitalismo, bem como aquelas subordinadas. 
Outra característica marcante do processo de reestruturação da produção é a expansão da mão de obra feminina, que abarca mais de $40 \%$ da força de trabalho em algumas nações de capitalismo avançado, e que tem sido absorvido pelo empresariado na condição de trabalho part-time. Antunes, aponta, por exemplo, o Reino Unido, onde desde 1998, o contingente feminino superou o masculino, na composição da força de trabalho britânica. No entanto, isso não tem configurou-se em igualdade de remuneração. Pelo contrário, o nível de remuneração das mulheres são em média inferiores aos dos homens. (1999, p. 105)

A ampliação do segmento de serviços nos últimos decênios é outro ponto que merece ser salientado da reorganização produtiva do capital. É importante frisar que o setor de serviços também incorporou as transformações que ocorreram em outros setores produtivos. Vale destacar que isso não implicou no crescimento das taxas de emprego. Pelo contrário, a tendência é o crescimento das filas de desempregados.

Como paliativo para uma situação dramática para os trabalhadores, muitos intelectuais comprometidos com a defesa da ordem capitalista, defendem a flexibilização da legislação que regula as relações entre capital e trabalho ou ainda, mudanças na educação escolar de forma a dotar os indivíduos de maior capacidade de adaptação diante dos "novos tempos". Tudo se passa como se não houvesse alternativas. A culpa pela exclusão é transferida ao próprio trabalhador.

A crescente taxa de desemprego dos jovens é outro dado alarmante presente no mundo contemporâneo. (CHESNAIS, 2008, p. 12) Além dos jovens, nota-se também o descarte de trabalhadores com mais de 40 anos e que, sem alternativas para o desemprego, procuram no trabalho informal ou precarizado uma alternativa para sobrevivência. Porém, os mesmos que apontam para as lacunas na formação do trabalhador para a exclusão do mercado de trabalho diante das transformações constantes, são os mesmos que "esquecem" de denunciar a utilização da mão de obra infantil ou do trabalho escravo em diferentes regiões do planeta nas mais variadas atividades produtivas, muitas das quais, atendendo indiretamente, na cadeia produtiva, as grandes empresas nacionais ou transacionais. A exemplo disso, os dados da Organização Internacional do Trabalho (OIT), revelam um dramático quadro do trabalho escravo.

- Existe um número estimado de 360 mil pessoas presas ao trabalho forçado em países industrializados, de um total de 12,3 milhões em todo o mundo;

- 270 mil trabalhadores forçados, $75 \%$ do total nos países industrializados, foram traficados;

- Os lucros estimados derivados do tráfico globalmente são de US\$ 32 bilhões, dos quais cerca de US\$ 15,5 bilhões são gerados nos países industrializados;

- O trabalho forçado imposto pelo estado em países industrializados atinge cerca de 5\% do total e consiste principalmente do trabalho nas prisões que é involuntário e contrário às normas internacionais

$\mathrm{Na}$ realidade, os dados apresentados não devem causar espanto para aqueles que conhecem a história das relações capitalistas. A miséria gerada pelas relações capitalistas contribui para a exploração brutal dos trabalhadores.

Lembremos também a liberdade de estabelecimento e de repatriação dos lucros das nas mais diferentes regiões do planeta. No atual contexto econômico, as unidades produtivas são relocadas em regiões que apresentam a maior probabilidade de reprodução do capital. Uma empresa, que sob o signo do fordismo, concentrava a sua produção dentro das fronteiras 
de seu domínio, hoje apresenta uma característica completamente diferente. Diante desse desenho produtivo, novas regiões industriais emergem e muitas desaparecem.

Neste ponto, é interessante relembrarmos que no Manifesto Comunista de Marx e Engels ultrapassa a descrição da ordem burguesa do século XIX, mas também expõe com clareza a essência do capitalismo, que continua predatória e destrutiva.

A burguesia não pode existir sem revolucionar permanentemente os instrumentos de produção - por conseguinte, as relações de produção e, com isso, todas as relações sociais. A conservação inalterada do antigo modo de produção era, pelo contrário, a condição primeira da existência de todas as anteriores classes industriais. A contínua subversão da produção e, com isso, todas as relações sociais, a permanente incerteza e a constante agitação distinguem a época da burguesia de todas as épocas precedentes. Dissolvemse todas as relações sociais antigas e cristalizadas, com o seu cortejo de representações e concepções secularmente veneradas; todas as relações que as substituem envelhecem antes de se consolidarem. Tudo o que era sólido e estável se dissolve no ar, tudo o que era sagrado é profanado e os homens são enfim obrigados a encarar, sem ilusões, a sua posição social e as suas relações recíprocas. (MARX, ENGELS, 1998, p. 8)

Diante do texto emergem algumas questões: as transformações ocorridas na organização da produção negam a essência apontada por Marx e Engels? O Estado não continua, em última instância, como "um comitê para administrar os negócios coletivos de toda a classe burguesa"? Neste marco, não seria precisamente a direção executiva do Estado que têm conduzido as políticas que normatizam o processo de flexibilização das relações de trabalho em defesa dos interesses do capital? levantadas.

Creio que os apontamentos de Chesnais indicam a resposta para as questões

A consolidação da mundialização, vista como regime funcionando em prol do capital concentrado, acentuou mecanismos de descentralização do capital. Conduziu também a um novo salto na polarização da riqueza e na evolução dos sistemas políticos em direção ao domínio de oligarquias econômicas e políticas dirigidas para o enriquecimento e a reprodução do seu domínio. São interesses que ditam as decisões responsáveis por acelerar a crise ecológica planetária, a qual ameaça diretamente a reprodução da vida entre os povos e as camadas sociais mais frágeis e vulneráveis. (CHESNAIS, 2008, p. 17-18)

Hoje a flexibilização das relações de trabalho é uma bandeira central da burguesia como instrumento de "superação" da crise. É claro que trata-se de uma proposta que visa a manutenção da ordem e que reforça a submissão dos trabalhadores à lógica do capital. Afinal, não podemos nos esquecer da necessidade da existência de um exército de reserva para a exploração do trabalho pelo capital. Dito de outra forma, o desemprego dos trabalhadores não é algo acidental, mas é fruto da dinâmica das relações materiais geradas pelo capitalismo. A expropriação do trabalhador tem sido uma necessidade histórica do capital para que refaça constantemente suas relações de dominação, de modo a garantir a extração da mais valia nas mais variadas formas vividas por nós. Dessa formulação depreende-se algo fundamental: não são as máquinas ou instrumentos de trabalho que descartam os trabalhadores; é o capital que os descarta, pois tal processo é condição para assegurar sua reprodução. 
Do ponto de vista da produção capitalista, realiza-se, assim, uma grande ruptura, pois o trabalho não depende mais das condições naturais e biológicas do trabalhador. Além disso, instaura-se uma grande diferença no processo de trabalho, porque o movimento global da fábrica não depende mais do trabalhador, mas da potência e da velocidade do sistema de máquinas combinadas. A máquina, que possui a capacidade de funcionamento uniforme, contínuo e regular, executa várias tarefas simultaneamente. O trabalhador transforma-se em peça humana que acompanha a máquina. Sua tarefa resume-se em manter a máquina em funcionamento. Ela a alimenta com as matérias necessárias à produção, lubrifica-a ou corrige possíveis falhas que podem aparecer no processo de funcionamento. Com o desenvolvimento do capitalismo, tais tarefas são também substituídas por mecanismos automáticos. A transformação das máquinas em autômatos mecânicos tem como consequência a eliminação não só das mãos, como também dos próprios homens. (AUED, 1999, p. 57)

Cabe ressaltar que Marx (1983), ao tratar do modo de produção capitalista, particularmente na obra $O$ capital, mostra-nos que se trata de um modo social de organização cuja estrutura tem como objeto central e permanente a maximização da acumulação do capital, a concentração e a centralização. Nas palavras de Frigotto (1996), é uma sociedade que produz para produzir.

Assim, se nossas observações estiverem corretas, é impossível negar que os processos de precarização e intensificação do trabalho docente estão inscritas nas alterações em curso no contexto de mundialização do capital. Afinal, a educação não está imune às transformações da base material, mas devemos compreendê-la como uma dimensão concreta da vida material e que se modela em consonância com as condições de existência dessa mesma sociedade.

\section{A construção da hegemonia neoliberal.}

A consolidação do Estado de bem estar social e das políticas keynesianas ocorreu de fato após a Segunda Guerra Mundial. No entanto, cabe esclarecer que a ascensão do keynesianismo vincula-se ao momento histórico que marca a crise iniciada em 1929 e que conduziu o capitalismo a um período recessivo. Como forma de superação da crise, o Estado americano adotou na década seguinte um conjunto de políticas econômicas orientadas nas propostas de John Maynard Keynes, que defendia a intervenção estatal para combater o desemprego. O término da Segunda Guerra Mundial inaugurou o que muitos denominam como os "anos de ouro do capitalismo", que diga-se de passagem, não foram tão reluzentes para todos. Nas palavras de Hobsbawm:

Hoje é evidente que a Era de Outro pertenceu essencialmente aos países capitalistas desenvolvidos, que, por todas essas décadas, representaram três quartos da produção do mundo, e mais de $80 \%$ de suas exportações manufaturadas. (...) Na verdade, de início pareceu que a parte socialista do mundo, recém-expandida, levava vantagem. A taxa de crescimento da URSS na década de 1950 foi mais veloz que a de qualquer país ocidental, e as economias da Europa Oriental cresceram quase com a mesma rapidez - mais depressa em países até então atrasados, mais devagar no já industrializados ou parcialmente industrializados. (HOBSBAWM, 2001, p. 255) 
$\mathrm{Na}$ verdade, o refluxo do liberalismo econômico atendia as necessidades do capital em um contexto marcado pela destruição gerada pela Segunda Guerra e pelas disputas entre EUA e URSS: a Guerra Fria. A constituição do chamado Estado de bem estar social respondia a duas questões importantes naquele momento: recuperar-se da guerra, além de deixar para trás os receios de uma revolução social e, o consequente avanço comunista, herança da Resistência. O crescimento acelerado que se seguiu levou muitos observadores a suporem que, de algum modo, seria eterno.

O mundo industrial, claro, se expandia por toda a parte: nas regiões capitalistas e socialistas e no "Terceiro Mundo". No velho Ocidente, houve impressionantes exemplos de revolução industrial, como a Espanha e a Finlândia. No mundo do "socialismo existente", países predominantes agrários como a Bulgária e a Romênia ganharam expressivos setores industriais. (...)

A economia mundial, portanto, crescia a uma taxa explosiva. $\mathrm{Na}$ década de 1960, era claro que jamais houvera algo assim. A produção mundial de manufaturas quadruplicou entre o início de 1950 e o início da década de 1970, e, o que é mais ainda impressionante, o comércio mundial de produtos manufaturados aumentou dez vezes. (HOBSBAWM, 2001, p. 256-257)

Porém, o rápido crescimento econômico do pós-guerra entrou em uma fase crítica, sobretudo no início da década de 1970. De fato, o anos que se seguem são marcados por como um período de reestruturação econômica e de reajustamento social e político. As novas tecnologias inseridas no âmbito da produção, a crise do Petróleo combinada com a redução do crescimento econômico e crescimento inflacionário contribuíram para a ascensão da ideologia neoliberal que já se encontra em gestação.

O esgotamento do padrão de acumulação do fordista/taylorista induziu o capital a buscar estratégias de recuperação das taxas de lucro através das propostas neoliberais, que enxergavam no Estado, e em suas políticas sociais, como o grande vilão da economia. Os intelectuais comprometidos com as bandeiras do neoliberalismo declaravam que as despesas do Estado com políticas públicas e o poder dos sindicatos destruíam os níveis necessários de lucro das empresas.

Assim sendo, como forma de gerenciar a sua crise estrutural, foi iniciado o processo de reestruturação do capital e de seu sistema jurídico e ideológico de dominação. A fórmula encontrada estaria no suposto "Estado-mínimo", ou seja, a ausência do poder público para as questões sociais, mas forte o suficiente para controlar os gastos públicos e enfraquecer os sindicatos, ao mesmo tempo que buscava-se a desregulamentação dos direitos trabalhistas, além da desmontagem do setor produtivo estatal.

Da perspectiva neoliberal, o equilíbrio monetário servia de parâmetro balizador de qualquer governo. Dessa forma, a concretização de reformas fiscais, percebida como diminuição dos impostos sobre o capital é defendido como pilar fundamental para incentivar a retomada da econômica. Nesse sentido, a alternativa do capitalismo para sua crise estrutural acarretou um processo de substituição do modelo industrial fordista e do modelo políticoeconômico Keynesiano pelo regime de acumulação flexível, fortalecendo o capital financeiro 
e especulativo em um momento de crise acentuada das experiências do chamado "socialismo real", que sem dúvida, auxiliou na difusão - entre muitos intelectuais - da ideia de que o liberalismo e a economia de mercado venceram em termos absolutos, e teriam se transformado em modelo permanente e categórico de organização da vida humana.

Nesse cenário, os Estados Nacionais, fortalecidos na defesa da ordem burguesa, com a privatização das empresas estatais e com promoção de políticas de defesa da liberdade econômica, fortalecem a defesa do mercado como agente regulador das relações sociais. Assim sendo, o discurso conservador neoliberal equipara tudo o que é estatal com a ineficiência, a corrupção e o desperdício, enquanto que a "iniciativa privada" surge sublimada como a esfera da competência administrativa, da probidade e da austeridade.

No ambiente político conservador dos anos 80/90, a queda do Muro de Berlim e a crise do chamado "socialismo real" passaram a servir, tanto no âmbito político quanto no pseudocientífico, para alardear as teses do fim da história, ou seja, fim do sentido de lutar-se pela utopia de uma sociedade socialista, fim do trabalho e o fim das classes sociais. Diante da agenda neoliberal, muitos intelectuais que se autoproclamavam como "socialistas" abandonaram uma perspectiva crítica, adotando como único caminho possível a Democracia e o capitalismo. É interessante notar também o abandono ou supressão de conceitos como como Trabalho, Capitalismo, Classes Sociais e Exploração, substituindo-os por categorias mais apropriadas aos interesses burgueses, tais como cidadania, inclusão social, equidade, entre outros.

A reestruturação produtiva, a crise econômica que abalava a legitimidade da ditadura no Brasil, além de um amplo processo de satanização do Estado produziu um ambiente ideológico amplamente favorável ao avanço do conservadorismo.

A direitização do clima ideológico e político do Ocidente nos anos 80 trouxe consigo um duplo movimento: por um lado, uma supersticiosa exaltação do mercado, fechando os olhos para os resultados catastróficos que seu funcionamento autônomo havia produzido no passado - até desembocar na Grande Depressão de 1929 - e absolvendo-o impiedosamente de suas culpas. Por outro, uma recíproca satanização do Estado como causador de todas as desgraças e infortúnios que, de diferentes maneiras, afetaram as sociedades capitalistas. (BORON, 1995, p. 77)

Da satanização do Estado advém a tese do Estado mínimo acompanhada de credo de fé que iguala tudo o que é estatal como sinônimo de ineficiência, corrupção e desperdício, enquanto o mercado é apresentado como o reino da austeridade e eficiência. Essa bandeira desfraldada pelos profetas da ordem não se sustenta à luz de pequenas evidências, entre elas, o simples fato de que a outra face da corrupção e da ineficiência Estado é o empresário privado que corrompe o funcionário estatal.

Diante desse quadro cabe-nos perguntar até que ponto a democracia em um Estado capitalista é capaz de superar as enormes diferenças entre a igualdade "celestial" proclamada através da lei e a desigualdade material produzida diuturnamente pelas relações capitalistas de produção? Em nosso entendimento, é evidente que o projeto societário do capital não supera, e nem poderá fazê-lo, os obstáculos intransponíveis do despotismo do capital. No que diz respeito as aspirações democráticas foram frustradas com as políticas de "ajustes" que excluíram e marginalizaram grandes segmentos da sociedade, que reforçaram em pouco tempo, o apartheid econômico e social. 
Observe-se se não é deprimente o panorama político da hegemonia burguesa sob o signo do neoliberalismo, sustentando-se sobre sociedades marcadas pelos antagonismos de classe, que condenam todos os dias milhares de homens e mulheres ao desemparo e à marginalidade. É evidente que o projeto de "democratização" sob a hegemonia do capital não pode ser considerado como algo sério, pois tropeça aqui com obstáculos intransponíveis, de natureza estrutural.

Pois bem, neste aspecto, verifica-se mais uma característica daquilo que é apresentado como "novidade", mas que é anacrônico e ideológico. Vivemos em uma sociedade marcada por antagonismos: produz-se mais com menos trabalho. A produtividade do trabalho nos cresceu de forma astronômica, mas a divisão do produto do trabalho fica restrito a poucas mãos. O que efetivamente vem a ser o discurso de "integração" pela educação em uma sociedade marcada pela divisão em classes sociais antagônicas? Seriam as reformas no âmbito da educação, dentro das propostas orientadas pelo mercado, uma resposta concreta para a crise do capitalismo, crise do trabalho assalariado, e à inserção material da classe que vive do trabalho em condições de igualdade aos demais segmentos?

\section{A valorização do trabalho docente: entre o proclamado e o real.}

No Brasil, o Estado que se configurou no Brasil a partir dos anos 1990 implementou uma série de reformas de caráter liberal e ampliou sua omissão nas questões sociais. Apesar da proclamada valorização do trabalho docente presente na Constituição Federal promulgada em 1988, no artigo 206, inciso cinco e na Lei de Diretrizes e Bases da Educação de 1996, não é isso que encontramos na prática. $O$ que se percebe é precisamente a desvalorização engendrada por uma série de fatores, tais como: as transformações no mundo do trabalho acompanhadas das políticas neoliberais, tais como redução do orçamento; políticas de controle do déficit fiscal; omissão do Estado nas questões sociais.

Como a educação não está isolada das contradições e problemas que estão presentes na arena social, o professor é mais uma das vítimas do modelo econômico marcado pela exclusão. Na verdade, o discurso dominante aponta o professor como "protagonista" da educação e cobra de sua atividade o máximo de produtividade e o mínimo de dispendido, isto é, com modestos salários. Vejamos os apontamentos de Saviani.:

Nessa nova conjuntura, como se situa o professor? O quarto ato de seu drama reveste-se de algumas particularidades. Continua-se pedido que ele seja eficiente e produtivo, mas agora ele não necessita seguir um planejamento rígido; não precisa pautar sua ação por objetivos predefinidos, seguindo a regras preestabelecidas. Como ocorre com os trabalhadores de modo geral, também os professores são instados a se aperfeiçoarem continuamente num eterno processo de aprender a aprender. Acena-se, então, com cursos de atualização ou reciclagem, dos mais variados tipos, referidos a aspectos particulares e fragmentados da atividade docente, todos eles aludindo a questões práticas do cotidiano. O mercado e seus porta-vozes governamentais parecem querer um professor ágil, leve, flexível; que, a partir de uma formação inicial ligeira, de curta duração e a baixo custo, prosseguiria sua qualificação no exercício docente lançando mão da reflexão sobre sua própria prática, apoiado eventualmente por cursos rápidos, ditos também "oficinas"; essas recorrendo aos meios informáticos, transmitiriam 
em doses homeopáticas, as habilidades que o tornariam competente nas pedagogias da "inclusão excludente", do "aprender a aprender" e da "qualidade total". Mas o exercício dessas competências não se limitaria à atividade docente propriamente dita. Pede-se aos professores que, no espírito da "qualidade total", não apenas ministrem aulas, mas também participem da elaboração do projeto pedagógico das escolas; da vida da comunidade, animando-a e respondendo às suas demandas; da gestão da escola e suprindo suas dificuldades específicas. (SAVIANI, 2008, p. 448-449) (grifo nosso)

Como se vê, as condições de trabalho dos professores também foram afetadas. É importante apontarmos que as questões ligadas à precarização do trabalho docente não são recentes em nosso país, ainda que tenham ganhado contornos dramáticos nos últimos anos, através da privatização direta ou indireta (substituição parcial ou total do poder público) e da adoção de normas sugeridas pelos órgãos internacionais, tais como o Banco Mundial, nas políticas públicas para educação.

Fundamentalmente, a partir dos anos 1970, evidencia-se o processo de agravamento progressivo das condições econômicas em nosso país e a precarização do ensino oferecido nas escolas mantidas pelo Estado, paralelo ao processo de expansão, repercutindo na prática de ensino nas escolas. Nas décadas seguintes, 1980/90, as influências dos organismos internacionais de financiamentos se acentuam, orientando os rumos da escolarização e da formação docente. As propostas oficiais (tanto em nível nacional como internacional) estão apoiadas nas modificações processadas nas engrenagens e mecanismos de funcionamento sociometabólico do capital. Nesse vasto campo de complexidades há um deslocamento do debate educacional do âmbito pedagógico para o "mercado de serviços educacionais" (LEHER, 2001, p.151).

Um diálogo com Frigotto (1995), nesse instante, é significativo. A linha de argumentação do texto Delírio da razão: crise do capital e metamorfose conceitual no campo educacional busca demonstrar como os conceitos e as categorias se metamorfoseiam ou se ressignificam, operando no campo ideológico, mistificando a compreensão da crise econômico-social, ideológica e ético-política do capitalismo real no fim do milênio e suas implicações nas atuais políticas educacionais do Brasil.

Para melhor elucidar a argumentação de Frigotto (1995) podemos observar que, de 1994 até o momento, as políticas públicas para educação brasileira vêm estabelecendo seus parâmetros nos moldes da "globalização" econômica, com vistas a sua inserção no mundo moderno, a partir de um modelo econômico "neoliberal" assumido como inevitável. As novas formas de organização do trabalho, desse modelo decorrentes, impuseram um novo tipo de formação, no qual o domínio do conhecimento e o tempo de escolarização passaram a ser estratégicos.

A inclusão do item "serviços educacionais" na pauta da Organização Mundial do Comércio (OMC) com o propósito de incluir os serviços públicos do mundo - educação, saúde, serviços sociais, transporte público - no Acordo Geral de Comércio e Serviços (AGCS ou GATS) e liberalizá-los estão em harmonia com essas diretrizes, os organismos internacionais, especialmente o Banco Mundial, elaboram documentos que balizam as políticas educacionais dos países subdesenvolvidos. No caso brasileiro uma infinidade de dispositivos legais e práticos ratificam essa compreensão. 
Em um contexto marcado pela crescente mundialização econômica, segundo o discurso dos intelectuais comprometidos com a defesa da ordem, os problemas enfrentados pelos sistemas educacionais devem ser resolvidos pelos parâmetros de competências definidos pelo mercado. $\mathrm{O}$ discurso neoliberal aplicado à educação baseia-se, fundamentalmente, sobre dois aspectos: o pressuposto de que a instituição escolar possa ser encarada como uma organização empresarial com fins lucrativos, segundo a ideia do mercado educacional livre e sem a interferência estatal; e a transposição de conceitos aplicados ao setor empresarial para a área educacional.

Dessa forma, os segmentos da educação básica, mantida pelo Estado e que atende principalmente aos filhos da classe que vive do trabalho, tornam-se alvos das demandas do capital, afora o fato de "contentar-se" com minguados recursos dos orçamentos públicos. Por isso, encontramos no âmbito da educação escolar a emergência de noções, supostamente novas, mas que de novo concebem fundamentalmente a ênfase ideológica: competências, habilidades, qualidade total, empregabilidade, etc. Vejamos os apontamentos de Cardozo sobre a questão:

Como a produção e a reprodução da ideologia são frutos do mesmo processo que reproduz a riqueza social como capital e o trabalho como trabalho assalariado, os idealizadores das reformas educativas em curso no Brasil procuram encobrir a exploração, quando não levam em conta a diversidade real, as diferenças entre os países ricos e pobres e as especificidades de cada região e Estado. Utilizam conceitos, concepções e expressões frutos de ideologia produzidas pelo capitalismo e procuram apresenta-los como normais e destituídos de conflitos e contradições.

A empregabilidade é um desses conceitos que cumpre uma função ideológica muito importante na sociedade capitalista contemporânea. Os trabalhadores precarizados - subcontratados, temporários, conta própria - são levados a incorporar a flexibilidade e a rotatividade como instrumentos de manutenção de sua empregabilidade. Os desempregados, além de assumirem a culpa pela situação de ser sem-emprego, são encorajados a usar a criatividade para inventar o próprio trabalho. (CARDOZO, 2008, p. 176-177)

Uma das consequências diretas da visão empresarial da educação escolar pode ser notada através do aviltamento das potencialidades das escolas mantidas pelo Estado em todos os níveis, além da organização de modelos empresariais, supostamente melhores, para medir a "produção" dos professores, por meio de processos avaliativos deliberados e implantados de forma autoritária, por ministérios, secretarias ou agências normatizadoras.

As iniciativas de reforma propostas pelo pensamento liberal incidem tanto na rede de escolas mantidas pelo Estado como nas redes de escolas privadas. Um exemplo que merece destaque é a figura do professor terceirizado. A questão foi tema de reportagem na Folha de São Paulo de 2006. A forma de contratação dos professores é semelhante a de outros profissionais também terceirizados e atende a uma demanda focalizada, liberando as mantenedoras de encargos trabalhistas, tais como tais como FGTS, férias e décimos terceiros salários. Um grande negócio à custa de uma mão de obra qualificada, porém, precarizada.

A falta de direitos trabalhistas gera insegurança, dizem professores cooperados. "Você sabe que não pode ficar doente, pois só recebe por aula 
dada", afirma um docente de ciências da computação da Faculdade Sumaré -alguns professores não quiseram ser identificados para evitar retaliações. "Como não temos outra opção, nos sujeitamos a isso. É a força do mercado", diz uma docente de ciências contábeis da mesma instituição. "Sem garantia, o emprego vira um bico. E todos pulam fora na primeira chance", afirma um professor de ciências da computação da Faculdade Drummond, que tem dois campi na zona leste. (Folha de São Paulo, 27/11/2006)

Em um momento marcado pelo crescente desemprego e pela fragilização dos sindicatos, os empresários aproveitam-se para impor regimes e contratos de trabalho mais flexíveis. Dessa forma, são evidentes os prejuízos pedagógicos, pois os professores não recebem qualquer benefício. A alta rotatividade também é corriqueira, uma vez que os professores não criam vínculos com aquele espaço educativo. Em grande medida, esta foi a "alternativa" encontrada pelas instituições particulares de ensino em São Paulo, conforme relato da reportagem, mas presente em outras regiões do Brasil.

Assim sendo, a precarização do trabalho docente deve ser compreendida no quadro das transformações em curso no mundo do trabalho no contexto de hegemonia das políticas neoliberais. Essa análise parte de uma concepção ampliada de trabalho e de trabalhadores, tal qual aponta a obra de Antunes (1999). Dito de outra forma, não se trata apenas de uma precarização do trabalho docente, mas da precarização do trabalho para o conjunto da classe trabalhadora.

É importante realçar que a elaboração, propagação e monitoramento das reformas neoliberais que avalizam a materialidade em um momento de mundialização do capital - estão sob a orientação política dos organismos internacionais do capital, como o Fundo Monetário Internacional, a Organização Mundial do Comércio Internacional, o Branco Mundial, Organização Mundial do Comércio, o Banco Interamericano de Desenvolvimento e a Organização para Cooperação e Desenvolvimento Econômico. Essas instituições políticas do capital tem uma atuação fundamental na organização dessas reformas neoliberais, principalmente nas nações latino-americanas, em irrestrita convergência com os valores encampados pelas burguesias locais. Dito de outra forma, não se trata de uma imposição como muitos querem enxergar, mas uma convergência de valores entre as agências e as elites locais.

Além dos parâmetros acima é importante pontuar a privatização da educação superior cujos critérios de "qualidade" são os empresariais. As consequências dessa compreensão são evidentes, acentua-se o atraso econômico e tecnológico do país, distancia-se o Brasil, cada vez mais, do anseio de se tornar um país da modernidade. Em sintonia com o contexto neoliberal marcado pela racionalização, desregulamentação, desestatização e liberalização, a educação foi veiculada como um dos elementos de composição na relação competitiva da economia e não apenas como um agente de resgate da dívida social. Ou seja os enfoques e paradigmas da educação buscaram desafios das transformações da economia, do capital e do trabalho (LIMA, 2006).

Ancorados nesses fatos é que assistimos, perplexos, à profusão de dispositivos legais e práticos que pressupõe a existência do outro no acordo, sendo esse outro os parâmetros do mercado. Em síntese, e considerando o que foi focalizado até aqui, as políticas sociais no Brasil, quando se universalizam, foram acompanhadas por uma queda na qualidade do atendimento. Nesse sentido, a quantidade foi muito mais valorizada pelo Estado e as elites do que a qualidade, que faz parte apenas da retórica política. Paralelamente a universalização da 
educação básica em nossas terras, também verificamos o crescimento da responsabilidade do professor pelo sucesso ou fracasso não apenas dos alunos, mas do próprio sistema de ensino.

No entanto, sabemos que o modelo educacional sempre vincula-se de forma profunda com as lutas entre interesses e perspectivas dos grupos em disputa de cada momento histórico. Dada a correlação forças nas arenas sociais, verificamos o comprometimento da função cultural da escola básica brasileira, fruto das condições materiais que incidem sobre o desenvolvimento de seu trabalho, tornando-a frágil e insuficiente, fundamentalmente para os filhos da classe que vive do trabalho.

Pensar a educação em sua totalidade significa compreender que o trabalho diário do professor não se resume apenas a prática pedagógica, mas requer também fundamentação teórica para o desenvolvimento de seu trabalho, estrutura física das escolas, organização do tempo e do espaço, jornada de trabalho adequada, salários compatíveis, plano de carreira, entre outros. Sem essas condições materiais, a tendência é que os professores não se reconheçam no produto de seu trabalho. Por isso, essa precarização é sentida nas nossas Instituições Educacionais, sejam básica ou superior.

Diante das relações materiais que se apresentam amplamente favorável ao capital, resta-nos o imperativo ético de refletirmos sobre a conquista de espaços que se coloquem a serviço da luta pela superação da ordem. Em outras palavras, é importante fortalecer um projeto contra-hegemonico. Projeto que esteja a serviço da "classe que vive do trabalho", mas não do mercado e do lucro das instituições empresariais.

\section{Considerações finais}

Os dados apresentados desnudam a necessidade de uma mudança na educação pública que supere a marca da privatização. Tentar vincular o desempenho educacional futuro do país a eventuais recursos incertos, utilizar frases de efeito, atribuir vagamente responsabilidades à "sociedade civil e empresários", ou divulgar intenções com discursos vazios de materialidade - ações que presenciamos reiteradamente - serão certamente infrutíferas e servirão apenas como um recurso ideológico para justificar a manutenção da ordem social.

Nesse sentido, diante do quadro de precarização do trabalho docente, cabe a nós, professores e servidores que trabalham no campo da educação, juntamente com a classe que vive do trabalho, comprometermo-nos com a defesa de uma educação pública e verdadeiramente popular. Nesse sentido, as palavras de Saviani são pertinentes:

Enfim, cabe insistir na íntima relação entre formação e trabalho docente deixando claro que a questão da formação de professores não pode ser dissociada do problema das condições de trabalho que envolve a carreira do magistério em cujo âmbito devem ser equacionadas as questões de salário e da jornada de trabalho. Com efeito, as condições precárias de trabalho não apenas neutralizam a ação dos professores, mesmo que fossem bem formados. Tais condições dificultam, também, uma boa formação, pois operam como fator de desestímulo à procura pelos cursos de formação docente e à dedicação aos estudos.

Ora, tanto para se garantir uma formação consistente como para se assegurar condições adequadas de trabalho faz-se necessário prover os recursos financeiros correspondentes. Aí está, portanto, o grande desafio a ser enfrentado. É preciso acabar com a duplicidade pela qual, ao mesmo tempo 
em que se proclamam aos quatro ventos as virtudes da educação exaltando sua importância decisiva num tipo de sociedade como esta em que vivemos, classificada como "sociedade do conhecimento", as políticas pela busca da redução de custos, cortando investimentos. Faz-se necessário ajustar as decisões políticas ao discurso imperante. (SAVIANI, 2007, p. 75)

Pelo que foi dito até aqui, ganha sentido a defesa da escola pública e a luta pela não abdicação do Estado de seu papel de provedor de bens públicos. Educação não é um serviço prestado, mas um direito que deve ser assegurado. Como indivíduos, seremos incapazes de transformar profundamente as estruturas vigentes. Portanto, é necessário fortalecer os agentes comprometidos com a escola popular no âmbito da sociedade civil, com o objetivo de exercer/ampliar o controle sobre o Estado. O fortalecimento das organizações de professores, dos movimentos estudantis e outras entidades afins, são fundamentais para a construção de uma nova sociedade. Assim, em lugar da defesa da privatização, o que se torna imprescindível é a necessidade de denunciar as práticas que ajudam a manter os privilégios presentes em nossa sociedade, sem nos esquercemos que a instituição escolar é reflexo das relações materiais de produção.

Por outro lado, é necessário ter clareza que a precarização do trabalho docente e a mercantilização da educação não será extinta por decreto. Tal fenômeno social é uma manifestação concreta da correlação de forças entre as diferentes classes e frações de classes que ocultaram, e ainda ocultam, através do discurso ideológico os interesses empresariais. Dessa forma, fica para os setores progressistas a tarefa de conquistar trincheiras dentro da sociedade civil na luta pela escola pública e popular, que negue a seletividade e o rebaixamento do ensino das camadas populares. Afinal, a história é um campo aberto de possibilidades no âmbito de suas determinações estruturais. Nesses termos, a educação que se processa na luta política, que se trava nas diferentes arenas sociais, tem um significado muito mais amplo, pois é aí que os indivíduos adquirem uma compreensão mais clara do processo histórico e educacional.

\section{Referências}

ANTUNES, R. Adeus ao trabalho? São Paulo: Cortez, 1995.

ANTUNES, R. Os sentidos do trabalho. São Paulo: Boitempo, 1999.

ADRIÃO, Theresa; PERONI, Vera (Orgs.). O público e o privado na educação: interfaces entre o Estado e sociedade. São Paulo: Xamã, 2005.

AUED, Bernadete Wrublevski. Sobre a extinção das profissões: implicações teóricas. In: AUED, Bernadete Wrublevski Educação para o (des) emprego: ou quando estar liberto da necessidade de emprego é um tormento. Petrópolis: Vozes, 1999.

BORON. Atílio. A sociedade civil depois do dilúvio neoliberal. IN: ANDERSON, Perry. Balanço do neoliberalismo. In: SADER, Emir: GENTILI, Pablo (Orgs.). Pós-neoliberalismo: as políticas sociais e o Estado democrático. Rio de Janeiro: Paz e Terra, 1995

BRASIL. Ministério da Educação. O Plano de Desenvolvimento da Educação. Razões, princípios e programas. Brasília: Inep, 2008. 
BRASIL. Ministério da Educação. Plano Nacional de Educação. Brasília: Inep, 2001.

BRASIL. Presidência da República. Decreto $\mathrm{n}^{\circ}$ 6.094, de 24 de abril de 2007. In www.planalto.gov.br (acessado em 19/03/2008).

CARVALHO, Alba Maria Pinho. GUERRA, Eliana, Costa. Tempos contemporâneos: trabalhadores supérfluos no fio da navalha da lógica do capital. In: SOUZA, Antônia de Abreu. NETO, Enéas de Araújo Arrais. FELIZARDO, Jean Mari. CARDOZO, Maria José Pires. BEZERRA, Tânia Serra Azul Machado (Orgs.) Trabalho, capital mundial e formação de trabalhadores. Fortaleza: Senac Ceará; Edições UFC, 2008.

CARDOZO, Maria José Pires Barros. A produção flexível e a formação do trabalhador: o modelo da competência e o discurso da empregabilidade. In: SOUZA, Antônia de Abreu. NETO, Enéas de Araújo Arrais. FELIZARDO, Jean Mari. CARDOZO, Maria José Pires. BEZERRA, Tânia Serra Azul Machado (Orgs.) Trabalho, capital mundial e formação de trabalhadores. Fortaleza: Senac Ceará; Edições UFC, 2008.

CHESNAIS, François. Mundialização do capital e jogo da lei da população inerente ao capitalismo. In: SOUZA, Antônia de Abreu. NETO, Enéas de Araújo Arrais. FELIZARDO, Jean Mari. CARDOZO, Maria José Pires. BEZERRA, Tânia Serra Azul Machado (Orgs.) Trabalho, capital mundial e formação de trabalhadores. Fortaleza: Senac Ceará; Edições UFC, 2008.

COUTINHO, Carlos Nelson. A democracia na batalha das idéias e nas lutas políticas do Brasil de hoje. In: FÁVERO, Osmar. SEMERANO, Giovanni. (Orgs.) Democracia e construção do público no pensamento educacional brasileiro. Petrópolis: Vozes, 2002

Folha de São Paulo. Ausência de direitos trabalhistas traz insegurança a terceirizados, $27 / 11 / 2006$

Declaração da OIT sobre os Princípios e Direitos Fundamentais no Trabalho e seu

Seguimento. Disponível em

http://www.oit.org.br/sites/all/forced_labour/oit/relatorio/paises_industrializados.pdf. Acesso em 20/10/2011.

FRIGOTTO, G. Delírio da razão: crise do capital e metamorfose conceitual no campo educacional. In: GENTILE, P. Pedagogia da exclusão: crítica ao neoliberalismo em educação.Petrópolis: Vozes, 1995.p.77-108.

FRIGOTTO, G. Educação e a crise do capitalismo real. São Paulo: Cortez, 1996.

HOBSBAWM, Eric. Era dos Extremos: o breve século XX (1914/1991) São Paulo: Companhia das Letras. 2001, p. 91

LEHER, Roberto. Projetos e modelos de autonomia e privatização das universidades públicas. In: GENTILE, P. (Org.). Universidade na penumbra: neoliberalismo e reestruturação universitária. São Paulo: Cortez, 2001. p.151-187.

LIMA, Rosângela Novaes. Políticas educacionais e a lógica neoliberal para a educação básica. In: GEMAQUE, Rosna Maria O.;LIMA, Rosângela Novaes. Políticas públicas educacionais: o governo Lula em questão. Belém: CEJUP, 2006. 
MARX, K. O capital: crítica da economia política. São Paulo: Abril Cultural, 1983. (Os Economistas).

MARX, K. ENGELS, F. O manifesto comunista. São Paulo. Cortez, 1998.

MÉSZÁROS, I. Para além do capital: rumo a uma teoria de transição. Campinas: Editora UNICAMP, Boitempo, 2002.

PAIVA, V. Revolução educacional e contradições da massificação do ensino. Contemporaneidade e educação, n. 3, 1998. p. 44-99

SAVIANI, Dermeval. História das ideias pedagógicas no Brasil. Campinas: Autores Associados, 2008.

Formação e condições de trabalho docente. In: Revista educação e cidadania. Campinas: Alínea, 2007.

VALOR ECONÔMICO. Colégios de SP vão terceirizar professor por causa da crise. Valor Econômico, 04/04/2004.

Recebido em novembro/2011

Aprovado em julho/2012 